\title{
Gear-Shaper Cutter with Curvilinear Side Flank Face
}

Roman Siecla, Stanislaw Legutko

Poznan University of Technology, Faculty of Mechanical Engineering and Management, Piotrowo 3 street, 60-965 Poznan, Poland, e.mail: roman.siecla@put.poznan.pl, stanislaw.legutko@put.poznan.pl

The paper presents a concept of the design of gear shaper cutters with curvilinear side flank faces. The problem of forming the outline of the cutting edge of the gear shaper wedge has been discussed and the possibilities of execution of this type of knives have been indicated. The method of forming the rake face of curvilinear side flank face has been presented.

Keywords: gear wheels, curvilinear flank face, gear shaper cutter design

\section{References}

[1] KUNSTETTER ST. Podstawy konstrukcji narzędzi skrawajacych. WNT. Warszawa 1980.

[2] NIESZPOREK T. Podstawy konstrukcji narzędzi skrawających do obróbki walcowych uzębień zewnętrznych. Wyd. Pol. Częst. Częstochowa 2004.

[3] NIESZPOREK T. SIECLA R. Analiza geometryczna dłutaka modułowego o uproszczonej technologii. Arch. Techn. Masz. i Aut. Poznań, Vol. 24 nr 1.

[4] VASILKO K. MACUROVÁ A. Two local extremes of cutting speed. Manufacturing Technology, Vol. 12 June 2012. ISSN 1213-2489. p. 86-89.

[5] KOCMAN K. Application of magnetic correlation analysis on the choice and correction of cutting parameters for automated manufacturing systems. Manufacturing Technology, Vol. XI December 2011. ISSN 1213-2489. p. 28-32.

[6] KUNDRÁK J. Alternative machining procedures of hardened steels. Manufacturing Technology, Vol. XI December 2011. ISSN 1213-2489. p. 32-39.

[7] MAKEDONSKI A. Unconventional machining method for enhancing the durability of tools and strength of the specimens bonded. Manufacturing Technology, Vol. XI December 2011, ISSN 1213-2489. p. 49-55.

[8] LUKOVICZ I. BÍLIK O. HOLEMY S. Development of Grinding Wheels for Tools Manufacturing. Manufacturing Technology. Vol. X December 2010. ISSN 1213-2489. p. 10-16.

[9] MÁDL J. Design for Machining. Manufacturing Technology, Vol. IX December 2009. ISSN 1213-2489. p. 8186.

[10] NOVAK, M. (2012). Surfaces with high precision of roughness after grinding. In Manufacturing Technology, vol. 12., no. 12., UJEP, Usti nad Labem, 66-70 pp.

[11] SIECLA R. Wieczorowski K. Modyfikacja zarysu koła zębatego, kształtowana powierzchnią natarcia standardowego dłutaka modułowego. ZN Pol. Rzesz. Mechanika. Z. 57. Rzeszów 2001.

[12] WIECZOROWSKI K. Studia nad procesem dłutowania obwiedniowego kół zębatych ewolwentowych dłutakiem modułowym. ZN. GOBiEN. Gorzów Wlkp. 1982.

[13] WIECZOROWSKI K. NIESZPOREK T. SIECLA R. Analiza geometryczna dłutaka modułowego z ostrzami o płaskich powierzchniach przyłożenia. W zb. pt.: Koła zębate. pod red. St. Legutko, K. Wieczorowski. Wyd. Kom Bud. Masz. PAN oddz. w Poznaniu. Poznań 2004.

[14] WIECZOROWSKI K. SIECLA R. Dłutak modułowy z ostrzami o bocznych powierzchniach przyłożenia ukształtowanych promieniowo. Mat. Konf. pt.: „Koła zębate KZ 2008”. Projektowanie, Wytwarzanie, Pomiary, Eksploatacja. Ofic. Wyd. Politechniki Rzeszowskiej. Rzeszów 2008. 